Journal of Engineering and Applied Sciences 15 (1): 128-140, 2020

ISSN: 1816-949X

(C) Medwell Journals, 2020

\title{
Wind Energy Potential Assessment in Selected Regions in Northern Cyprus Based on Weibull Distribution Function
}

\author{
${ }^{1,2}$ Youssef Kassem, ${ }^{1}$ Hüseyin Çamur, ${ }^{2}$ Sama A.M. Abughinda and ${ }^{3}$ Ali Şefik \\ ${ }^{1}$ Department of Mechanical Engineering, Faculty of Engineering, \\ Near East University, 99138 Nicosia Cyprus \\ ${ }^{2}$ Department of Civil Engineering, Faculty of Civil and Environmental Engineering, \\ Near East University, 99138 Nicosia Cyprus \\ ${ }^{3}$ Faculty of Engineering, Cyprus International University, 99138 Nicosia Cyprus
}

\begin{abstract}
This study investigates the wind characteristics and available wind energy for six stations in Northern Cyprus, namely Famagusta, Rizokarpaso, Ercan, Nicosia, Kyrenia and Morphou. Based on 7 year (2010-2016) wind data recorded at these stations, Weibull distribution using three different methods called maximum likelihood (MLM), moment (MM) and least squares (LSM) methods were used for the statistical analysis of the obtained data at a height of $10 \mathrm{~m}$. The power law model is utilised to determine the yearly and monthly mean wind speed at various heights of 30,50, 80 and $90 \mathrm{~m}$. Moreover, Wind Power Density (WPD) was estimated using three numerical methods. The results illustrated that Famagusta is the most applicable location for harvesting the kinetic energy of the wind, while Rizokarpaso has been classified as the second most applicable site. Furthermore, power density results indicated that the wind energy source in these regions is categorized to be very poor. Consequently, it is concluded that the average wind powers indicate that small-scale wind turbines are more suitable than high capacity wind turbines in the selected regions.
\end{abstract}

Key words: Northern cyprus, power density, wind data, weibull distribution

\section{INTRODUCTION}

Renewable energy conversion systems are popular due to the emerging need for clean energy production throughout the world and wind energy conversion systems are one of the fastest growing alternatives among these renewable technologies. Before investing in a wind energy harvesting system at a certain location, the available wind energy (potential) and the feasibility of utilizing a wind energy conversion system need to be assessed in order to use the full potential of the available kinetic energy that wind can provide. The first parameters that need to be considered are the speed and characteristics of the wind at concerned location (Wagner and Mathur, 2012; Al Zohbi et al., 2015).

Many studies have been successfully conducted based on the mathematical methods known as Weibull and Rayleigh distributions to investigate the wind energy potential of different regions around the world. Al Zohbi et al. (2015), Rehman et al. (1994), Soulouknga et al. (2018) have investigated wind energy potential by using the method known as Weibull distribution. However, Pishgar-Komleh and Akram (2017), Ozay and Celiktas (2016), Gokcek et al. (2007) Turk and Kizi (2008), Katinas et al. (2017) conducted their research by comparing both Weibull and Rayleigh distributions. The general trend in these comparison studies is that Weibull distribution has surpassed Rayleigh distribution, apart from a study conducted in Kyrgyzstan (Turk and Kizi, 2008). This study revealed that Rayleigh distribution is more suitable to represent the wind characteristics in that particular location.

The analysis presented for Lithuania Katinas et al. (2017) also reviewed different methods for calculating the Weibull parameters, which concluded that it is more feasible to use MLM (Maximum Likelihood Method) and MSSDM (Mean Wind Speed and Standard Deviation Methods) in that region. Moreover, the recent publication of Aries et al. (2018) presents an intensive assessment of eight different distribution models, which also concluded that Weibull distribution is the best fit for wind data gathered for that specified region. Furthermore, Jaramillo and Borja (2004) reported that Weibull distribution is not a sufficient model for analysing wind energy potential in some parts of the world because of unique wind characteristics. In La Venta (Mexico), they successfully utilised the bimodal probability density function to best fit the regional wind data.

Cyprus is the third largest island in the Mediterranean and it does not have an electricity interconnection with neighboring countries. Therefore, the energy demands of the island need to be satisfied by local generation of 
power. In the last decade, there has been a sharp increase in the population of Northern Cyprus, mainly due to the international tourism and higher education sectors (Katircioglu, 2010). Consequently, the growth of the population has led to an increase in energy demand, where nearly all of the energy production is currently dependent on fossil fuels.

The increased energy demand and related environmental problems caused by burning fossil fuels has raised interest in alternative energy sources. In this regard, the objective of this study is to evaluate the wind energy potential of the northern part of the island based on six selected locations, namely Famagusta, Nicosia, Rizokarpaso, Ercan, Kyrenia and Morphou. The possibility of utilizing wind energy conversion systems to support electricity production was determined by using mathematical methods reported in the literature.

In the present study, wind speed data have been collected from the Meteorological Department, where wind speeds were measured using a cup anemometer at a height of $10 \mathrm{~m}$. Wind speed data was collected for the seven-year period between January, 2010 and December, 2016. Moreover, measured wind speed data have been extrapolated to heights of 30, 50, 80 and $90 \mathrm{~m}$. Monthly distribution parameters, the probability of observing wind and wind directions are evaluated for the selected cities. Furthermore, Weibull distribution is used to determine the wind characteristics, where three different methods were used to determine the Weibull parameters and wind power densities at different heights were analysed to evaluate wind energy potential.

Analysis procedure: This section reviews the theoretical background necessary for the analysis applied in this research to investigate the potential of the wind energy in Northern Cyprus. Firstly, two-parameter Weibull distribution is presented and then maximum likelihood, moment and least square methods are summarised, which are used to determine the distribution parameters. Lastly, mathematical relations employed to analyse wind power density and extrapolation of wind speed at different heights are delivered.

Statistical analysis: The statistical analysis of the data collected from the Meteorological Department starts with calculating the wind speed distributions for each city. It is crucial to accurately determine the probability distribution of the wind data during the statistical analysis.

As mentioned in the previous section, Weibull distribution is widely and successfully utilized to evaluate wind speed characteristics when analysing the wind energy potential of the interested region. A function that gives the probability distributions of the wind speeds can be expressed with the following equation (Sinden, 2007; Dahmouni et al., 2011; Kamau et al., 2010; Kaplan, 2017; Ahmed, 2018):

$$
f(v)=\left(\frac{k}{c}\right)\left(\frac{v}{c}\right)^{k-1} e^{-\left(\frac{v}{c}\right)^{k}}
$$

where, $f(v)$ represents the probability of observing wind speed, if $\mathrm{v}<0$, then $\mathrm{f}(\mathrm{v})=0$, vis the wind speed, $\mathrm{c}$ is the scale parameter in $\mathrm{m} / \mathrm{s}(\mathrm{c}>1)$ and $\mathrm{k}$ is the shape factor of distribution $(k>0)$. The shape of the best fit curve of the distribution can vary depending on the values of $k$ and c. Moreover, the cumulative distribution function for Weibull distribution is expressed with the relation given below (Sinden, 2007; Dahmouni et al., 2011; Kamau et al., 2010; Kaplan, 2017; Ahmed, 2018);

$$
\mathrm{F}(\mathrm{v})=1-\exp \left[-\left(\frac{\mathrm{v}}{\mathrm{c}}\right)^{\mathrm{k}}\right]
$$

Both equations depend on wind speed, scale parameter and shape factor. Determination of these parameters plays an important role when analysing the wind characteristics.

Estimation of Weibull scale and shape parameters: The importance of the accurate determination of distribution parameters has previously been mentioned and there are a variety of methods that can be used to find these values. The authors of this study decided to use three different methods found in the literature. These methods are called the maximum likelihood (MLM), Moment (MM) and Least Squares Methods (LSM).

Maximum Likelihood Method (MLM): This method evaluates the parameters of the distribution function in a time-series format. Generally, this method may require a higher number of iterations when compared to the other methods. However, it is very popular among similar studies due to its simplicity. The equations that are used to determine the scale and shape parameters of the distribution are given as (Kaplan, 2017; Ahmed, 2018; Rocha et al., 2012):

$$
\begin{gathered}
\mathrm{k}=\left(\frac{\sum_{1}^{\mathrm{n}} \mathrm{v}_{\mathrm{i}}^{\mathrm{k}} \ln \left(\mathrm{v}_{\mathrm{i}}\right)}{\sum_{1}^{\mathrm{n}} \mathrm{v}_{\mathrm{i}}^{\mathrm{k}}}-\frac{\sum_{1}^{\mathrm{n}} \ln \left(\mathrm{v}_{\mathrm{i}}\right)}{\mathrm{n}}\right)^{-1} \\
\mathrm{c}=\left(\frac{1}{\mathrm{n}} \sum_{1}^{\mathrm{n}} \mathrm{v}_{\mathrm{i}}^{\mathrm{k}}\right)^{1 / k}
\end{gathered}
$$

where, $n$ is used to represent the total number of data points in a particular period of time and $v_{i}$ is the speed of the wind measured at the interval i.

\section{MATERIALS AND METHODS}

Moment Method (MM): This method is one of the oldest among the other methods used to evaluate the distribution 
parameters (Rocha et al., 2012; Allouhi et al., 2017). It uses the first two instances of the distribution function to calculate the parameters of the Weibull distribution function. Iterative resolution of the following equations can be used to apply the method (Rocha et al., 2012; Allouhi et al., 2017):

$$
\begin{gathered}
\overline{\mathrm{v}}=\mathrm{c} \Gamma\left(\frac{1}{\mathrm{k}}+1\right) \\
\sigma=\mathrm{c}\left[\Gamma\left(1+\frac{2}{\mathrm{k}}\right)-\Gamma^{2}\left(1+\frac{2}{\mathrm{k}}\right)\right]^{1 / 2}
\end{gathered}
$$

where, $\bar{v}$ is the mean wind speed, $\sigma$ is the standard deviation of the data and $\Gamma$ is the gamma function.

Least Squares Method (LSM): The last method employed in this study is the least squares method, which is very popular among the solutions that are not accepted as estimation problems in applied engineering and mathematics. This method constructs a linear relationship for the two variables and optimizes their relationship. The expressions below can be used to do the calculations (Ahmed, 2018; Azad et al., 2015; Chaurasiya et al., 2017):

$$
\begin{gathered}
\mathrm{k}=\frac{\mathrm{n} \sum_{1}^{\mathrm{n}} \ln (\mathrm{v}) \times \ln [-\ln \{1-\mathrm{F}(\mathrm{v})\}] \sum_{1}^{\mathrm{n}} \ln (\mathrm{v}) \sum_{1}^{\mathrm{n}} \ln [-\ln \{1-\mathrm{F}(\mathrm{v})\}]}{\mathrm{n} \sum_{1}^{\mathrm{n}} \ln \left(\mathrm{v}^{2}\right)-\left\{\sum_{1}^{\mathrm{n}} \ln (\mathrm{v})\right\}^{2}} \\
\mathrm{c}=\exp \left[\frac{\mathrm{k} \sum_{1}^{\mathrm{n}} \ln (\mathrm{v})-\sum_{1}^{\mathrm{n}} \ln [-\ln \{1-\mathrm{F}(\mathrm{v})\}]}{\mathrm{nk}}\right]
\end{gathered}
$$

Wind power density: The theoretically available kinetic energy that wind possesses at a certain location can be expressed as the mean Wind Power Density (WPD). In other words, it is the maximum available wind power at each unit area. The mathematical expression for wind power density is given with the following relation (Irwanto et al., 2014; Yaniktepe et al., 2013):

$$
\overline{\mathrm{P}}=\frac{1}{2} \rho \overline{\mathrm{v}}^{3}
$$

where, $\overline{\mathrm{P}}$ is the available power for wind per unit area in $\mathrm{W} \mathrm{m} \mathrm{m}^{-2}$ and $\rho$ is the density of air in $\mathrm{kg} \mathrm{m}^{-3}$ $\left(1.225 \mathrm{~kg} \mathrm{~m}^{-3}\right.$ at $1 \mathrm{~atm}$ and 15$)$. The average wind velocity and the standard deviation of the data $(\sigma)$ are defined as:

$$
\overline{\mathrm{v}}_{\mathrm{i}}=\frac{1}{\mathrm{n}} \sum_{\mathrm{i}=1}^{\mathrm{n}} \mathrm{v}_{\mathrm{i}}
$$

$$
\sigma=\left[\frac{1}{n-1} \sum_{i=1}^{n}\left(v_{i}-\bar{v}_{i}\right)^{2}\right]^{1 / 2}
$$

Periodic wind power density per unit area (Monthly or annually) is given with the following expression (Yaniktepe et al., 2013):

$$
\overline{\mathrm{P}}_{\mathrm{w}}=\frac{1}{2} \rho c^{3} \Gamma\left(1+\frac{3}{\mathrm{k}}\right)
$$

The total amount of wind energy density $\left(\mathrm{W} . \mathrm{h} / \mathrm{m}^{2}\right)$ for a specific period can be calculated with the following equation (Irwanto et al., 2014):

$$
\mathrm{E}=\overline{\mathrm{P}} \mathrm{T}
$$

where, $\mathrm{T}$ is the time period in hours.

Extrapolation of wind data at different heights: Wind data retrieved from the Meteorological Department were acquired at a height of 10 meters from the ground and local speed of the wind scales up as the height in the atmosphere increases. The height of wind conversion systems can vary from 5-90 $\mathrm{m}$ depending on the type of the conversion system used. Therefore, it is necessary to extrapolate the wind data at increased heights to evaluate the full wind energy potential of the interested region. The power law model can be used to perform this extrapolation and its mathematical relation can be express with the following equation (Irwanto et al., 2014; Ali, 2010):

$$
\frac{\mathrm{v}_{\mathrm{z}}}{\mathrm{v}_{10}}=\left(\frac{\mathrm{z}}{\mathrm{z}_{10}}\right)^{\alpha}
$$

where, $\mathrm{v}_{\mathrm{z}}$ represents the required wind speed at the height of $\mathrm{z}$. is the wind speed data measured at the height of $10 \mathrm{~m}$. The exponent $\alpha$ is thesurface roughness coefficient which varies according to the structure of the landscape at the location and it needs to be determined empirically. Generally, it is difficult to obtain the precise value of this coefficient where there is a lack of experimental data. The formula given below can be used to estimate this coefficient (Irwanto et al., 2014; Ali, 2010):

$$
\alpha=\frac{0.37-0.088 \ln \left(\mathrm{v}_{10}\right)}{1-0.088 \ln \left(\mathrm{z}_{10} / 10\right)}
$$

Another common approach is to extrapolate the distribution parameters rather than extrapolating the wind speed data. Shape and scale parameters of the Weibull 
distribution function can be extrapolated to different heights using the relations given below (Safari and Gasore, 2010):

$$
\begin{gathered}
\mathrm{c}(\mathrm{z})=\mathrm{c}_{0}\left(\frac{\mathrm{z}}{\mathrm{z}_{10}}\right)^{\mathrm{n}} \\
\mathrm{k}(\mathrm{z})=\frac{\mathrm{k}_{0}\left[1-0.088 \ln \left(\frac{\mathrm{z}_{10}}{10}\right)\right]}{\left[1-0.088 \ln \left(\frac{\mathrm{z}_{10}}{10}\right)\right]}
\end{gathered}
$$

where, $\mathrm{c}_{0}$ and are the scale and shape factors determined for the measured height, $\mathrm{z}_{10}$ is the height of the wind speed measurements and $\mathrm{z}$ is extrapolation height. The exponent $n$ can be calculated by the relation given below (Safari and Gasore, 2010):

$$
\mathrm{n}=\frac{\left[0.37-0.088 \ln \left(\mathrm{c}_{0}\right)\right]}{1-0.088 \ln \left(\frac{\mathrm{z}}{10}\right)}
$$

Wind data measurement: The evaluation of the available wind energy necessitates the comprehensive knowledge of the wind characteristics at a particular region. Wind data that is analyzed in this study has been collected from 6 different stations constructed by the Meteorological Department. The cup type anemometers are used to gather the wind speeds where each measurement instrument was at a eight of $10 \mathrm{~m}$ above the ground.

Wind speed measurements were performed continuously at each station during the period from 2010 to 2016. The department supplied the data as an average value for each minute and the hourly mean values of the wind speeds were determined by these $1 \mathrm{~min}$ average values. Details of the location and landscape characteristics of each measurement station are presented in Fig. 1 and Table 1.

In this study, the wind data obtained from the six stations are adapted for the investigation of wind characteristics. Wind speeds and wind directions were recorded continuously during from the period from 2010-2016. The comprehensive geographic data of the selected stations are listed in Table 1 and Fig. 1.

\section{RESULTS AND DISCUSSION}

This section presents the results and discussions of the analysis conducted throughout this study. It starts with a description of the data obtained from the department followed by a presentation of the wind speed frequency distribution calculated at a height of $10 \mathrm{~m}$ for each location. Next, wind speeds at various heights will be discussed and frequency distributions at $90 \mathrm{~m}$ will be illustrated. Finally, wind frequency and their directions at Famagusta will be presented by using wind rose graphs.

Description of wind speed data: Variations of the monthly mean wind speeds at each station for the years from 2010-2016 are illustrated in Fig. 2. Moreover, the figure also shows the overall monthly mean wind speeds for the entire measurement period.

The average monthly wind speeds at Famagusta vary from 3.7-7.2 $\mathrm{m} \mathrm{sec}^{-1}$ and the general trend is that the mean wind speed decreases from March to August and then starts to increase afterwards for the rest of the year. Likewise, the values at Rizokarpaso indicate similar behaviour, where the minimum mean wind speeds are observed in October. The mean wind speeds in Rizokarpaso are in the range of 2.3-6.2 $\mathrm{m} \mathrm{sec}^{-1}$, whereas, the minimum average speed at Ercan is $2.6 \mathrm{~m} \mathrm{sec}^{-1}$ in October and the maximum values of $4.8 \mathrm{~m} \mathrm{sec}^{-1}$ are observed in March. In the graph plotted for Nicosia, the lowest wind speeds are around $1.5 \mathrm{~m} \mathrm{sec}^{-1}$ during November and highest values appear in June as

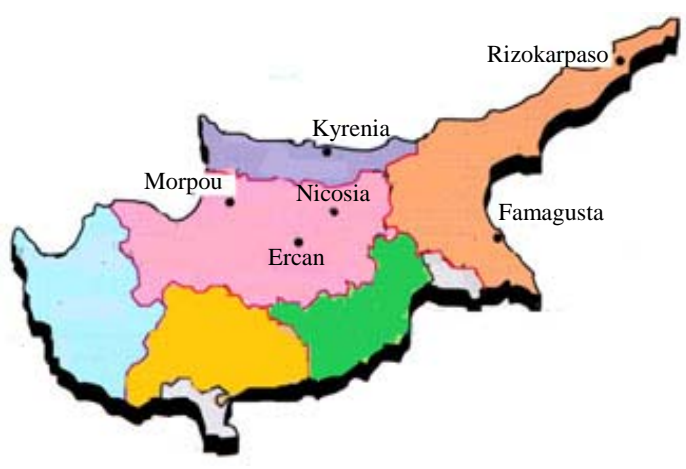

Fig. 1: Location of the sites used in this study

Table 1: Details of each station involved in the research

\begin{tabular}{llcc} 
& Coordinates & & \\
Station & Latitude $\left({ }^{\circ} \mathrm{N}\right)$ & Longitude $\left({ }^{\circ} \mathrm{E}\right)$ & Characteristics of the station \\
\hline Famagusta & $35^{\circ} 06^{\circ} 54$ & $34^{\circ} 24^{\prime} 31$ & Coastal \\
Rizokarpaso & $35^{\circ} 37^{\prime} 36$ & $33^{\circ} 30^{\prime} 00$ & Coastal \\
Ercan & $35^{\circ} 09^{\prime} 34$ & $33^{\circ} 21^{\prime} 33$ & Airport \\
Nicosia & $35^{\circ} 10^{\prime} 08$ & $33^{\circ} 19^{\prime} 08$ & Surrounded by buildings \\
Kyrenia & $35^{\circ} 20^{\prime} 25$ & $32^{\circ} 59^{\prime} 38$ & Coastal \\
Morphou & $35^{\circ} 11^{\prime} 53$ & & Coastal \\
\hline
\end{tabular}



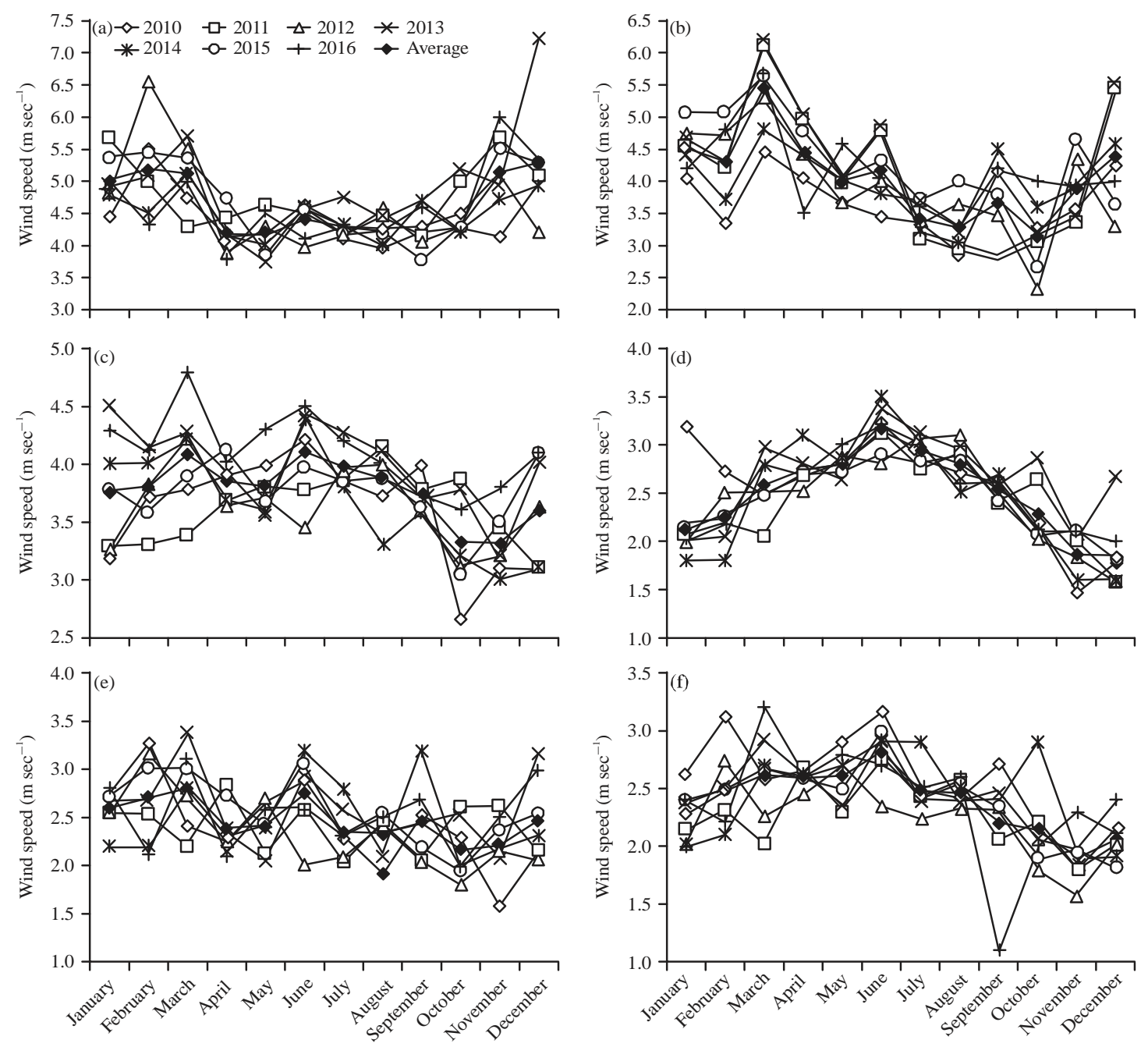

Fig. 2(a-f): Monthly variation of the mean wind speed (a) Famagust, (b) Rizokarpaso, (c) Ercan, (d) Nicosia, (e) Kyrenia and (f) Morphou

$3.5 \mathrm{~m} \mathrm{sec}^{-1}$. The average values for Kyrenia and Morphou illustrate that the minimum and maximum average wind speeds vary between approximately 1.1 and $3.4 \mathrm{~m} \mathrm{sec}^{-1}$ for both stations.

The hourly variations of the mean wind speeds for each year from 2010-2016 have been presented in Fig. 3. Furthermore, the overall hourly average wind speed variation for the entire measurement period from 2010-2016 has also been illustrated.

It is evident from the charts in Fig. 3. that similar patterns within the $24 \mathrm{~h}$ period are observed. The hourly average wind speeds slowly decrease early in the mornings and then start to increase until they reach a peak. After the highest values of the period, wind speeds are observed to decrease in all measurement stations, except at Famagusta and Rizokarpaso.
The average wind speed at the Famagusta station decreases from 1-8 a.m and shows a sharp increase afterward, where it reaches its maximum value at around 1 p.m. The wind speeds decrease after 1 p.m in Famagusta until 8 p.m and the mean values show a marginal increase through the night. A similar trend can be observed in Rizokarpaso until 6 p.m, where the mean values show fluctuations. There is initially another increase until 10 p.m and then it decreases until 12 p.m.

Overall, it can be determined from the data in Fig. 3. that the coastal areas record maximum average wind speeds late in the afternoon and the minimum value occurs between 4 and 6 a.m. In contrast, the maximum wind speeds were observed at 2 p.m and the minimum speeds were between 3 and 4 a.m. in Nicosia, which is the capital city of the country with the highest building density. At Ercan station, which is characterised by its 

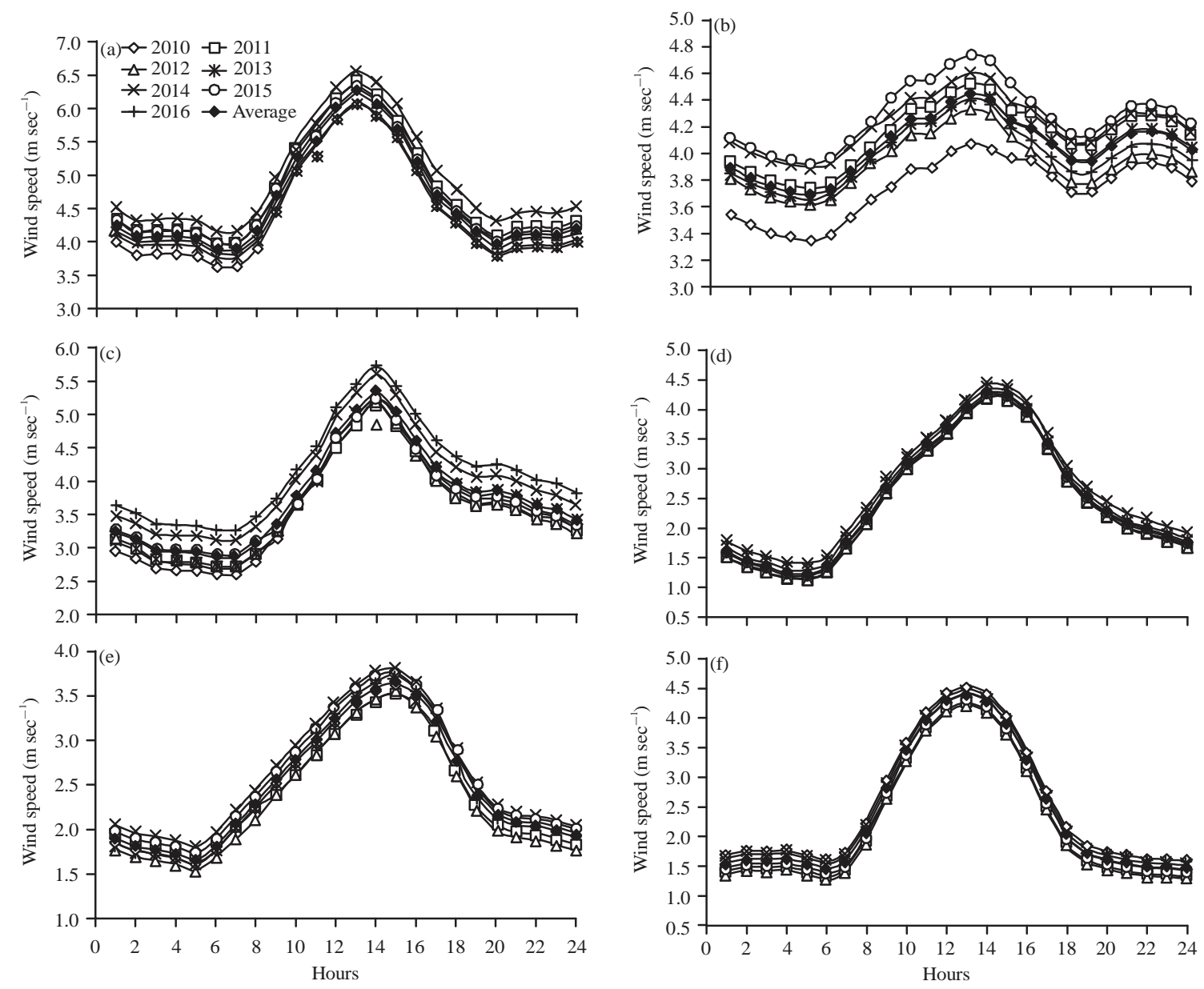

Fig. 3(a-f): Hourly variation of the mean wind speed (a) Famagust, (b) Rizokarpaso, (c) Ercan, (d) Nicosia, (e) Kyrenia and (f) Morphou

airport location, the maximum measurements are between 2 and 4 p.m. and the minimum wind speeds are measured after midnight between 2 and 3 a.m.

Wind speed frequency distribution at $10 \mathrm{~m}$ height: Table 2 illustrates the shape (k) and scale (c) values evaluated at each location for the entire wind data obtained for the 6 year period between 2010 and 2016 . The table compares the parameters that are calculated by the three different methods discussed previously (MLM, MM and LSM).

It can be easily noted that the highest and lowest shape parameters refer to Rizokarpazo and Morphou, respectively. The highest value was found to be 24.61 and the lowest was 2.45. Additionally, the maximum scale parameter was calculated as $5.02 \mathrm{~m} \mathrm{sec}^{-1}$ in Famagusta and the minimum as $2.58 \mathrm{~m} \mathrm{sec}^{-1}$ in Morphou. The method that is used to calculate these extreme values is MLM except the minimum scale parameter, which is calculated by the LSM method.
Furthermore, Table 2 presents the coefficient of determination $\left(\mathrm{R}^{2}\right)$ for the calculated parameters by different methods. $\mathrm{R}^{2}$ values vary between 0.972-0.997, which is sufficiently high for such an analysis and MLM has the highest coefficient of determination among the methods with an $\mathrm{R}^{2}$ value. This corresponds to the power densities of 68.49, 42.14, 37.68, 15.05, 11.72 and $14.36 \mathrm{~W} \mathrm{~m}^{-2}$ at Famagusta, Rizokarpaso, Ercan, Nicosia, Kyrenia and Morphou, respectively.

Additionally, the performance of three numerical methods (MLM, MM and LSM) in estimating Weibull distribution parameters were compared yearly between 2010 and 2016. All ' $k$ ' and 'c' values were determined individually by each method for each year and compared with the parameters calculated with the whole data (Table 2).

Figure 4 presents the yearly variations of the shape and scale parameters for the 7 year period in six different locations. It can be noted that the calculated yearly $\mathrm{k}$ parameter does not show significant differences 
throughout the years for all measurement locations. However, the c parameter shows profound changes during the measurement period. For example, the c values calculated for the years of 2013 and 2016 at the Ercan station show substantial differences when compared to the rest of the calculated values. This can lead to misleading conclusions if one performs analysis with insufficient data. This emphasises the importance of increasing the measurement range when analysing a weather-related data set.

Table 2: Weibull parameters for each station (2010-2016) at a height of $10 \mathrm{~m}$

\begin{tabular}{|c|c|c|c|c|c|}
\hline Methods & $\mathrm{k}$ & $\mathrm{c}\left(\mathrm{m} \mathrm{sec}^{-1}\right)$ & Mean $\left(\mathrm{m} \mathrm{sec}^{-1}\right)$ & $\mathrm{WPD}\left(\mathrm{W} \mathrm{m}^{-2}\right)$ & $\mathrm{R}^{2}$ \\
\hline \multicolumn{6}{|l|}{ Famagusta } \\
\hline MLM & 5.93 & 5.02 & 4.65 & 68.49 & 0.997 \\
\hline MM & 6.87 & 5.00 & 4.67 & 67.51 & 0.991 \\
\hline LSM & 8.75 & 4.89 & 4.62 & 63.62 & 0.995 \\
\hline Actual data & - & - & 4.65 & 61.48 & - \\
\hline \multicolumn{6}{|l|}{ Ercan } \\
\hline MLM & 5.36 & 4.11 & 3.79 & 37.68 & 0.983 \\
\hline MM & 6.87 & 4.06 & 3.79 & 36.25 & 0.972 \\
\hline LSM & 6.55 & 4.03 & 3.75 & 35.31 & 0.975 \\
\hline Actual data & - & - & 3.77 & 32.77 & - \\
\hline \multicolumn{6}{|l|}{ Kyrenia } \\
\hline MLM & 4.12 & 2.76 & 2.5 & 11.72 & 0.996 \\
\hline MM & 4.77 & 2.73 & 2.5 & 11.16 & 0.985 \\
\hline LSM & 4.92 & 2.68 & 2.45 & 10.47 & 0.993 \\
\hline Actual data & - & - & 2.48 & 9.33 & - \\
\hline \multicolumn{6}{|l|}{ Rizokarpaso } \\
\hline MLM & 24.61 & 4.18 & 4.09 & 42.14 & 0.985 \\
\hline MM & 24.59 & 4.15 & 4.06 & 41.16 & 0.973 \\
\hline LSM & 22.04 & 4.15 & 4.05 & 40.9 & 0.98 \\
\hline Actual data & - & - & 4.05 & 40.62 & - \\
\hline \multicolumn{6}{|l|}{ Nicosia } \\
\hline MLM & 2.8 & 2.88 & 2.56 & 15.05 & 0.996 \\
\hline MM & 2.76 & 2.87 & 2.55 & 15 & 0.99 \\
\hline LSM & 3 & 2.79 & 2.49 & 13.24 & 0.994 \\
\hline Actual data & - & - & 2.51 & 9.67 & - \\
\hline \multicolumn{6}{|l|}{ Morphou } \\
\hline MLM & 2.45 & 2.76 & 2.45 & 14.36 & 0.991 \\
\hline MM & 2.76 & 2.73 & 2.43 & 12.98 & 0.983 \\
\hline LSM & 3.34 & 2.58 & 2.31 & 10.08 & 0.985 \\
\hline Actual data & - & - & 2.4 & 8.45 & - \\
\hline
\end{tabular}
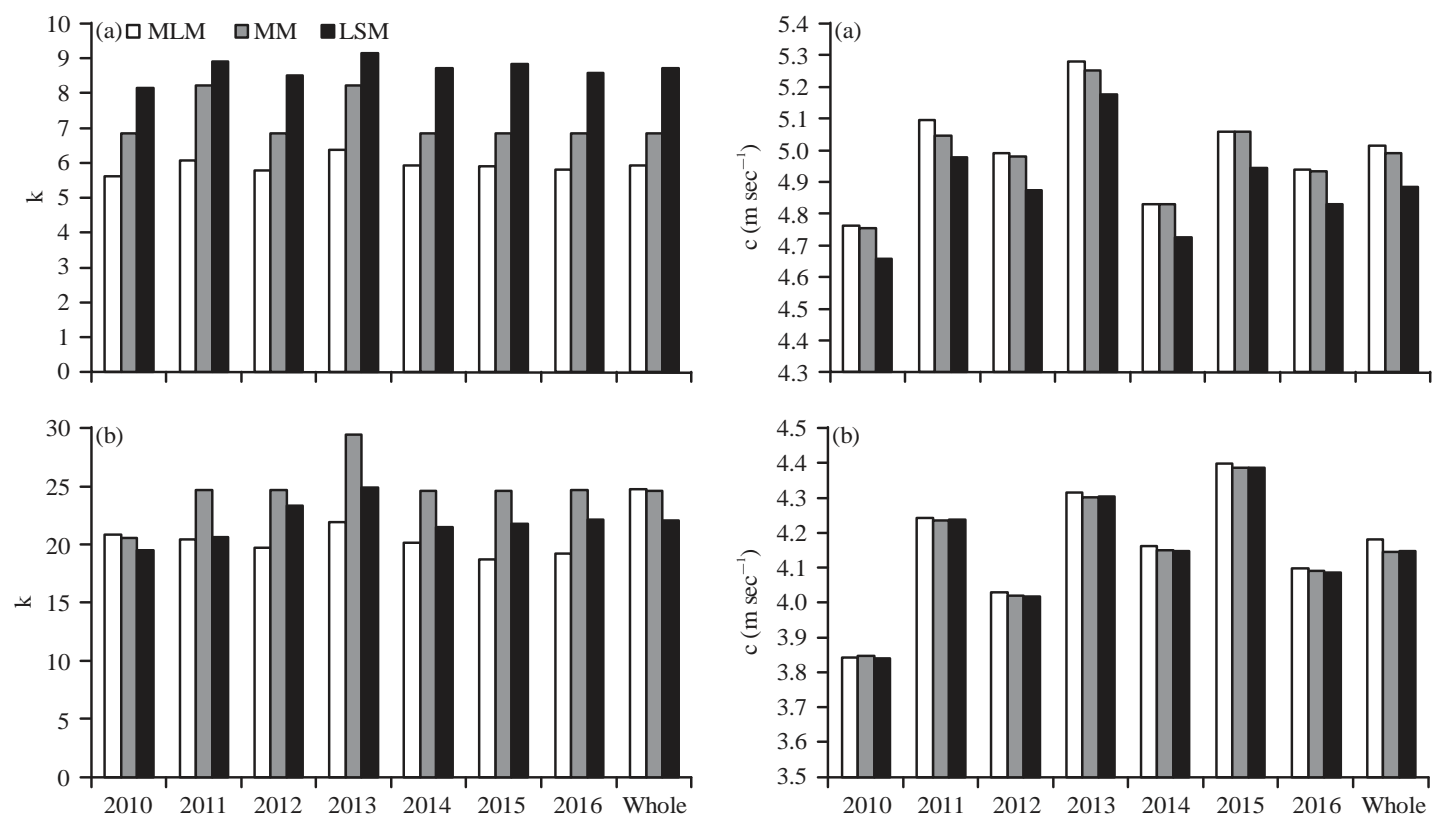

Fig. 4(a-f): Continue 

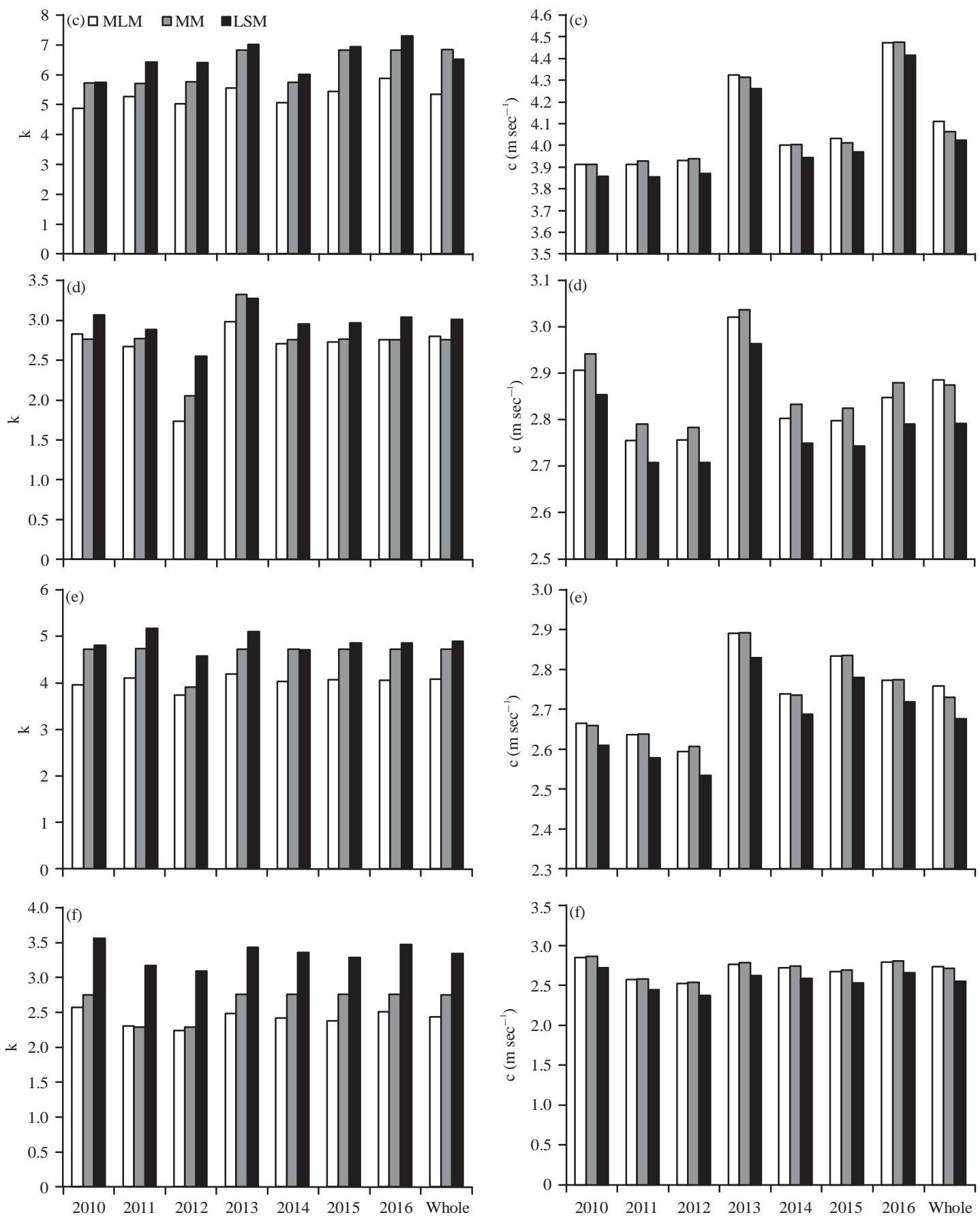

Fig. 4(a-f): Yearly variation of shape and scale parameters for the areas (a) Famagust, (b) Rizokarpaso, (c) Ercan, (d) Nicosia, (e) Kyrenia and (f) Morphou

Moreover, the annual wind speed frequency distribution data from each station are presented in Fig. 5 for the years from 2010-2016. Additionally, a comparison between three parameter estimation methods (MLM, MM and LSM) and the observed data is also given in the same figure. In fact, it can be noted that the fitted probability frequency models in Fig. 5 and Table 2 show that the Weibull probability frequency based on MLM is capable of providing a sound estimation of the observed wind speed data that is collected from each station.

Wind speed information at various height: The optimum wind speed for a typical wind turbine should 

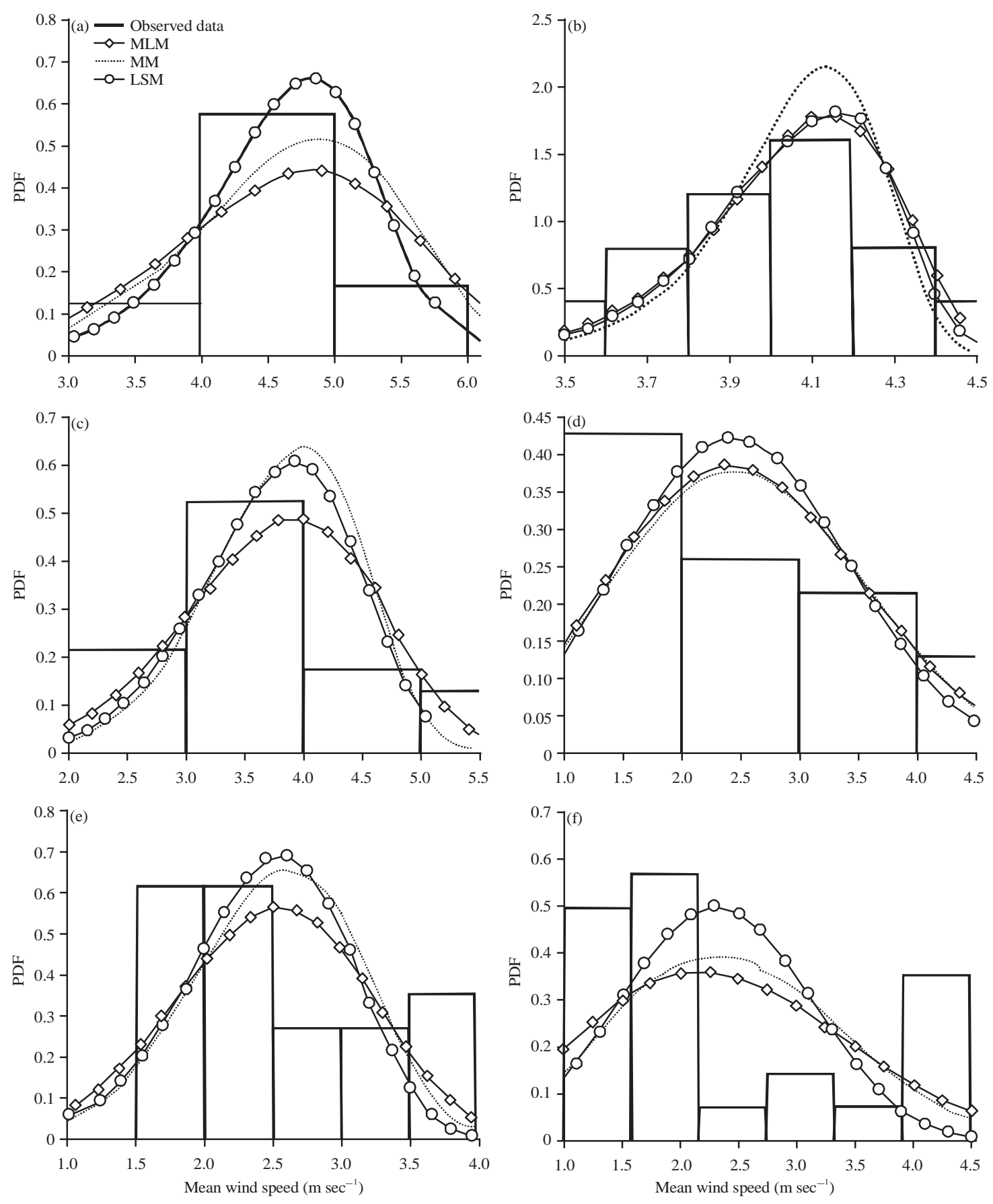

Fig. 5(a-f):Wind speed probability frequency for the whole (2010-2016) at height $10 \mathrm{~m}$ (a) Famagust, (b) Rizokarpaso, (c) Ercan, (d) Nicosia, (e) Kyrenia and (f) Morphou

be equal to or higher than $6.7 \mathrm{~m} \mathrm{sec}^{-1}$. At the same time, it is important to note that wind speeds higher than $11 \mathrm{~m} \mathrm{sec}^{-1}$ can be dangerous; therefore, it is not safe to invest in wind turbine in the regions that have a wind speed of more $11 \mathrm{~m} \mathrm{sec}^{-1}$ wind speed during the year (Ali, 2010). The roughness coefficient is expressed by the exponent $\alpha$, which is associated with the characteristics of the land surface and its value varies between 0.05 and 0.5 (Ahmed, 2018; Ali, 2010). The surface roughness values $(\alpha)$, determined by using Eq. 15 for different locations, are given in Table 3.

In this study, annual mean wind speeds are estimated for different heights of 30,50, 80 and $90 \mathrm{~m}$ by using the roughness coefficients listed in Table 3 . Wind speed 
Table 3: Roughness values for different sites

\begin{tabular}{|c|c|c|c|c|c|}
\hline \multicolumn{4}{|l|}{ Locations } & \multicolumn{2}{|r|}{ Roughness value $(\alpha)$} \\
\hline Famagusta & & & & \multicolumn{2}{|r|}{$\begin{array}{l}0.235 \\
0.247\end{array}$} \\
\hline \multicolumn{4}{|l|}{ Rizokarpaso } & \multirow{2}{*}{\multicolumn{2}{|c|}{$\begin{array}{l}0.247 \\
0.253\end{array}$}} \\
\hline \multicolumn{4}{|l|}{ Ercan } & & \\
\hline \multicolumn{4}{|l|}{ Nicosia } & \multicolumn{2}{|r|}{0.289} \\
\hline \multicolumn{4}{|l|}{ Kyrenia } & \multicolumn{2}{|r|}{0.290} \\
\hline \multicolumn{4}{|l|}{ Morphou } & \multicolumn{2}{|r|}{0.293} \\
\hline$\frac{\text { Table 4: Wei }}{\text { Methods }}$ & each s & $\frac{16) \text { at } 90 \mathrm{~m}}{\mathrm{c}\left(\mathrm{m} \mathrm{sec}^{-1}\right)}$ & Mean $\left(\mathrm{m} \mathrm{sec}^{-1}\right)$ & $\mathrm{WPD}\left(\mathrm{W} / \mathrm{m}^{2}\right)$ & $\mathrm{R}^{2}$ \\
\hline \multicolumn{6}{|l|}{ Famagusta } \\
\hline MLM & 5.94 & 8.37 & 7.76 & 317.53 & 0.979 \\
\hline MM & 6.88 & 8.35 & 7.8 & 314.83 & 0.971 \\
\hline LSM & 8.76 & 8.18 & 7.74 & 299.05 & 0.976 \\
\hline Calculated* & - & - & 7.79 & 288.96 & - \\
\hline \multicolumn{6}{|l|}{ Ercan } \\
\hline MLM & 5.33 & 7.12 & 6.56 & 196.37 & 0.965 \\
\hline MM & 6.84 & 7.07 & 6.61 & 191.61 & 0.952 \\
\hline LSM & 6.55 & 7.02 & 6.55 & 187.49 & 0.956 \\
\hline Calculated* & - & - & 6.58 & 173.97 & - \\
\hline \multicolumn{6}{|l|}{ Kyrenia } \\
\hline MLM & 4.06 & 5.17 & 4.69 & 77.32 & 0.978 \\
\hline MM & 4.72 & 5.14 & 4.70 & 74.58 & 0.965 \\
\hline LSM & 4.92 & 5.06 & 4.64 & 70.96 & 0.974 \\
\hline Calculated* & - & - & 4.68 & 62.80 & - \\
\hline \multicolumn{6}{|l|}{ Rizokarpaso } \\
\hline MLM & 20.33 & 7.15 & 6.96 & 208.53 & 0.967 \\
\hline MM & 20.23 & 7.12 & 6.93 & 205.75 & 0.953 \\
\hline LSM & 22.04 & 7.13 & 6.96 & 208.25 & 0.961 \\
\hline Calculated* & - & - & 6.97 & 206.97 & - \\
\hline \multicolumn{6}{|l|}{ Nicosia } \\
\hline MLM & 2.75 & 5.35 & 4.76 & 97.62 & 0.978 \\
\hline MM & 2.72 & 5.34 & 4.75 & 97.62 & 0.97 \\
\hline LSM & 3.00 & 5.25 & 4.69 & 88.62 & 0.975 \\
\hline Calculated* & - & - & 4.74 & 65.16 & - \\
\hline \multicolumn{6}{|l|}{ Morphou } \\
\hline MLM & 2.42 & 5.18 & 4.59 & 95.46 & 0.990 \\
\hline $1 \mathrm{MM}$ & 2.74 & 5.15 & 4.58 & 87.17 & 0.983 \\
\hline LSM & 3.34 & 4.91 & 4.41 & 69.66 & 0.985 \\
\hline Calculated* & - & - & 4.56 & 58.06 & - \\
\hline
\end{tabular}

*The mean wind speed at a height of $90 \mathrm{~m}$ and WPD were calculated using Eq. 14 and 9, respectively

increases as one moves higher above the ground and this variation is called the wind shear profile. Figure 6 presents the wind shear profiles at six different locations that are included in this study.

Data collected from each site at a height of $10 \mathrm{~m}$ have been extrapolated to the height of $90 \mathrm{~m}$, which is characterized as a good to very good wind resource height in the literature (Ali, 2010). For example, the $90 \mathrm{~m}$ synthesized data for Famagusta (based on the results of wind power density which is given in the previous section) is illustrated in Fig. 7. It can be noted from the figure that synthesized data at a height of $90 \mathrm{~m}$ shows good agreement with the observed data.

Table 4 tabulates the resultant parameters of Weibull at a height of $90 \mathrm{mfor}$ the methods used in this study. The coefficient of determination parameters are between 0.952 and 0.979 and the MLM method possesses the highest $\mathrm{R}^{2}$ value. When the MLM method is used, the estimated power density at an extrapolated height of $90 \mathrm{~m}$ varies from 77.32-317.53 $\mathrm{W} \mathrm{m}^{-2}$. The highest calculated power density values are $317.53 \mathrm{~W} \mathrm{~m}^{-2}$ at Famagusta, while

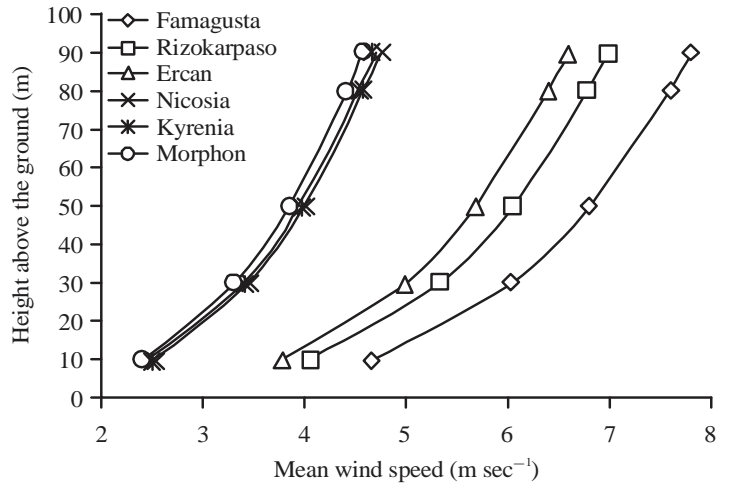

Fig. 6: Vertical wind shear profile at six studied locations

the minimum WPD was observed at Kyrenia with $77.32 \mathrm{~W} \mathrm{~m}^{-2}$. For comparison purposes, the calculated annual WPD at heights of 30, 50 and $80 \mathrm{~m}$ are presented in Table 5.

The kinetic energy potential of the wind at each site is characterised by the mean power density ranges given 
Table 5: Annual wind power density at various heights

\begin{tabular}{|c|c|c|c|c|}
\hline \multirow[b]{2}{*}{ Height (m) } & \multirow[b]{2}{*}{ Station } & \multicolumn{3}{|l|}{ Variables } \\
\hline & & Mean $\left(\mathrm{m} \mathrm{sec}^{-1}\right)$ & WPD $\left(\mathrm{W} \mathrm{m}^{-2}\right)$ & Wind power class \\
\hline \multirow[t]{6}{*}{30} & Famagusta & 6.02 & 133.50 & Poor \\
\hline & Rizokarpaso & 5.31 & 91.89 & \\
\hline & Ercan & 4.98 & 75.65 & \\
\hline & Nicosia & 3.45 & 25.20 & \\
\hline & Kyrenia & 3.40 & 24.17 & \\
\hline & Morphou & 3.31 & 22.13 & \\
\hline \multirow[t]{6}{*}{50} & Famagusta & 6.78 & 191.30 & \\
\hline & Rizokarpaso & 6.03 & 134.15 & \\
\hline & Ercan & 5.67 & 111.53 & \\
\hline & Nicosia & 4.00 & 39.23 & \\
\hline & Kyrenia & 3.95 & 37.72 & \\
\hline & Morphou & 3.84 & 34.67 & \\
\hline \multirow[t]{6}{*}{80} & Famagusta & 7.58 & 266.37 & \\
\hline & Rizokarpaso & 4.58 & 58.95 & \\
\hline & Ercan & 6.38 & 159.36 & \\
\hline & Nicosia & 4.58 & 58.95 & \\
\hline & Kyrenia & 4.53 & 56.79 & \\
\hline & Morphou & 4.41 & 52.42 & \\
\hline
\end{tabular}

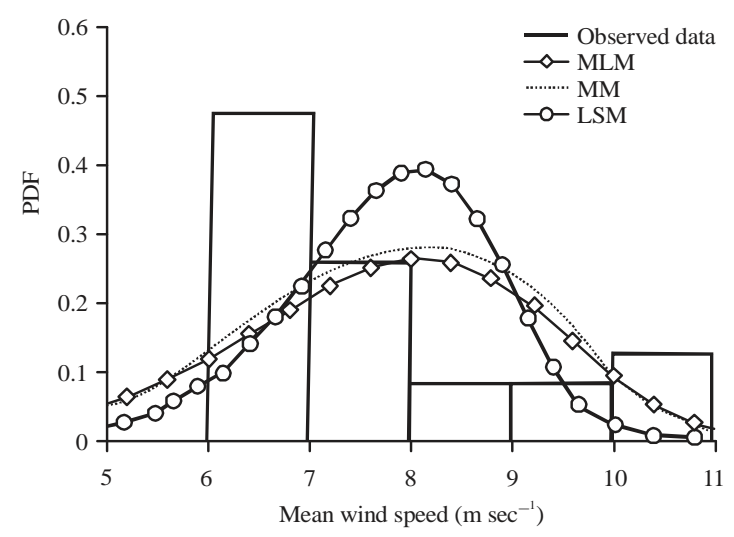

Fig. 7: Wind speed probability frequency for the whole (2010-2016) at height $90 \mathrm{~m}$

in the literature (Bilir et al., 2015; Mohammadi and Mostafaeipour, 2013). Among the sites investigated in this study, the maximum estimated power density became prominent in the Famagusta area, where the highest density is $299.05 \mathrm{~W} / \mathrm{m}^{2}$ at a height of $90 \mathrm{~m}$ (Table 4). According to the results listed in Tables 4 and 5 and the mean power density ranges found in the literature, all of the locations chosen for investigation indicate poor wind energy potential. Therefore, high capacity wind turbines (MWs) are not feasible to be investigated in these areas. Nevertheless, small-scale wind turbines can be used to gather the wind energy potential in these locations.

Wind frequency and rose: The data obtained from The Meteorological Department also included the direction of the wind for each day and month for the investigated years (2010-2016), where a higher wind frequency indicated the main direction. As mentioned previously,

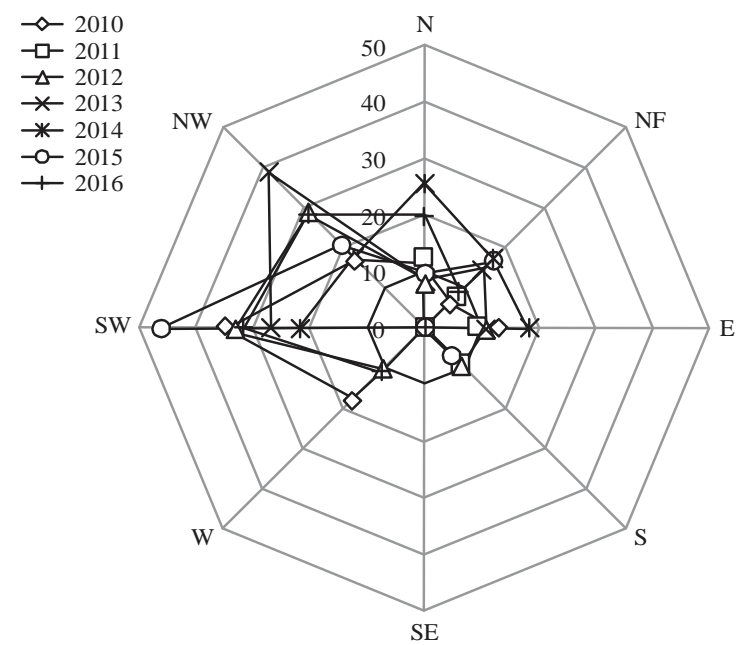

Fig. 8: Wind rose for the wind speed data (2010-2016) of Famagusta

Famagusta has the maximum mean wind speed and power density among the locations studied. Therefore, the wind rose representation of the wind energy frequency in Famagusta is presented in Fig. 8.

The highest frequency is found to be from the southwest with an occurrence of $46.35 \%$. The next direction that has a high frequency of occurrence is the northwest with $38.68 \%$. It can therefore be stated that if one installs a fixed wind turbine in Famagusta, it should be directed to the southwest or northwest.

\section{CONCLUSION}

In order to reduce the greenhouse gases and the dependency on the power plants that operate with imported fuels, wind energy potential in Northern Cyprus 
has been investigated by the data collected from The Meteorological Department. The wind speed and its direction from 2010-2016 have been investigated for the six stations. Average wind speed, wind speed occurrence and Weibull parameters and wind directions have been studied and presented in the form of graphs, tables and wind rose graphs. Wind speeds and powers at different heights were estimated by Weibull factors. It is important to note that this step was implemented after the wind analysis at $10 \mathrm{~m}$ and after determining the most accurate method for Weibull distribution (MLM, MM, and LSM. The following conclusions can be drawn from the conducted study: The studied area has average wind speeds of more than $2 \mathrm{~m} \mathrm{sec}^{-1}$. The highest wind speed was found to be $7.2 \mathrm{~m} \mathrm{sec}^{-1}$ in December at the Famagusta station and the lowest wind speed was $1.1 \mathrm{~m} \mathrm{sec}^{-1}$ in September in Morphou. The results identified that Famagusta possesses the highest wind energy potential among the sites investigated. Wind frequency that is shown in wind rose graphs revealed that the best wind direction for Famagusta is the southwest or northwest. All of the locations investigated in the study indicated poor wind characteristics. The average wind powers indicate that small-scale wind turbines are more suitable than high capacity wind turbines in the selected regions.

\section{REFERENCES}

Ahmed, A.S., 2018. Wind energy characteristics and wind park installation in Shark El-Ouinat, Egypt. Renewable Sustainable Energy Rev., 82: 734-742.

Al Zohbi, G., P. Hendrick and P. Bouillard, 2015. Wind characteristics and wind energy potential analysis in five sites in Lebanon. Intl. J. Hydrogen Energy, 40: 15311-15319.

Ali, M., 2010. Feasibility study of harnessing wind energy for turbine installation in province of Yazd in Iran. Renewable Sustainable Energy Rev., 14: 93-111.

Allouhi, A., O. Zamzoum, M.R. Islam, R. Saidur, T. Kousksou, A. Jamil and A. Derouich, 2017. Evaluation of wind energy potential in Morocco's coastal regions. Renewable Sustainable Energy Rev., 72: 311-324.

Aries, N., S.M. Boudia and H. Ounis, 2018. Deep assessment of wind speed distribution models: A case study of four sites in Algeria. Energy Convers. Manage., 155: 78-90.

Azad, A.K., M.G. Rasul, R. Islam and I.R. Shishir, 2015. Analysis of wind energy prospect for power generation by three Weibull distribution methods. Energy Procedia, 75: 722-727.
Bilir, L., M. Imir, Y. Devrim and A. Albostan, 2015. An investigation on wind energy potential and small scale wind turbine performance at İncek region-Ankara, Turkey. Energy Convers. Manage., 103: 910-923.

Chaurasiya, P.K., S. Ahmed and V. Warudkar, 2017. Study of different parameters estimation methods of Weibull distribution to determine wind power density using ground based Doppler SODAR instrument. Alexandria Eng. J., 57: 2299-2311.

Dahmouni, A.W., M.B. Salah, F. Askri, C. Kerkeni and S.B. Nasrallah, 2011. Assessment of wind energy potential and optimal electricity generation in Borj-Cedria, Tunisia. Renewable Sustainable Energy Rev., 15: 815-820.

Gokcek, M., A. Bayulken and S. Bekdemir, 2007. Investigation of wind characteristics and wind energy potential in Kirklareli, Turkey. Renewable Energy, 32: 1739-1752.

Irwanto, M., N. Gomesh, M.R. Mamat and Y.M. Yusoff, 2014. Assessment of wind power generation potential in Perlis, Malaysia. Renewable Sustainable Energy Rev., 38: 296-308.

Jaramillo, O.A. and M.A. Borja, 2004. Bimodal versus Weibull wind speed distributions: An analysis of wind energy potential in La Venta, Mexico. Wind Eng., 28: 225-234.

Kamau, J.N., R. Kinyua and J.K. Gathua, 2010. 6 years of wind data for Marsabit, Kenya average over $14 \mathrm{~m} \mathrm{sec}^{-1}$ at $100 \mathrm{~m}$ hub height: An analysis of the wind energy potential. Renewable Energy, 35: 1298-1302.

Kaplan, Y.A., 2017. Determination of the best Weibull methods for wind power assessment in the southern region of Turkey. IET. Renewable Power Gener., 11: 175-182.

Katinas, V., M. Marciukaitis, G. Gecevicius and A. Markevicius, 2017. Statistical analysis of wind characteristics based on Weibull methods for estimation of power generation in Lithuania. Renewable Energy, 113: 190-201.

Katircioglu, S.T., 2010. International tourism, higher education and economic growth: The case of North Cyprus. World Economy, 33: 1955-1972.

Mohammadi, K. and A. Mostafaeipour, 2013. Using different methods for comprehensive study of wind turbine utilization in Zarrineh, Iran. Energy Convers. Manage., 65: 463-470.

Ozay, C. and M.S. Celiktas, 2016. Statistical analysis of wind speed using two-parameter Weibull distribution in Alaçatı region. Energy Convers. Manage., 121: 49-54.

Pishgar-Komleh, S.H. and A. Akram, 2017. Evaluation of wind energy potential for different turbine models based on the wind speed data of Zabol region, Iran. Sustainable Energy Technol. Assess., 22: 34-40. 
Rehman, S., T.O. Halawani and T. Husain, 1994. Weibull parameters for wind speed distribution in Saudi Arabia. Solar Energy, 53: 473-479.

Rocha, P.A.C., R.C. de Sousa, C.F. de Andrade and M.E.V. de Silva, 2012. Comparison of seven numerical methods for determining Weibull parameters for wind energy generation in the northeast region of Brazil. Applied Energy, 89: 395-400.

Safari, B. and J. Gasore, 2010. A statistical investigation of wind characteristics and wind energy potential based on the Weibull and Rayleigh models in Rwanda. Renewable Energy, 35: 2874-2880.

Sinden, G., 2007. Characteristics of the UK wind resource: Long-term patterns and relationship to electricity demand. Energy Policy, 35: 112-127.
Soulouknga, M.H., S.Y. Doka, N. Revanna, N. Djongyang and T.C. Kofane, 2018. Analysis of wind speed data and wind energy potential in Faya-Largeau, Chad, using Weibull distribution. Renewable Energy, 121: 1-8.

Turk Togrul, I. and M. Imas Kizi, 2008. Determination of wind energy potential and wind speed data in Bishkek, Kyrgyzstan. Intl. J. Green Energy, 5: 157-173.

Wagner, H. and J. Mathur, 2012. Introduction to Wind Energy Systems: Basics, Technology and Operation. 2nd Edn., Springer, Berlin, Germany, ISBN:9783642329753, Pages: 106.

Yaniktepe, B., T. Koroglu and M.M. Savrun, 2013. Investigation of wind characteristics and wind energy potential in Osmaniye, Turkey. Renewable Sustainable Energy Rev., 21: 703-711. 